\title{
TIPOS, ORGANIZAÇÃO E VISIBILIDADE DE INFORMAÇÕES EM PÁGINAS INICIAIS DE WEBSITES DE UNIVERSIDADES BRASILEIRAS
}

\author{
TYPES, ORGANIZATION, AND VISIBILITY OF INFORMATION OF BRASILIAN \\ UNIVERSITIES' WEBSITE
}

Lígia Dias de Freitas ${ }^{1}$

Resumo: Apresenta pesquisa realizada com o objetivo de investigar a relação entre o tipo de informação disponibilizada nas páginas iniciais de websites de universidades brasileiras e a forma como ela está organizada, especificamente: verificar a visibilidade dada a cada tipo de informação por meio da área utilizada nas páginas iniciais dos websites das universidades escolhidas; identificar a visão das universidades em relação a seus websites; e relacionar tipos de informação disponibilizadas e tipos de organização nas páginas iniciais dos websites das universidades. Para isto, o artigo discorre sobre Arquitetura de Informação, a presença das universidades na web e o papel de suas páginas iniciais. A motivação da pesquisa baseia-se na identificação de um padrão para as informações organizadas nos websites de universidades, visto que estes agregam conteúdo para diferentes públicosalvo. As universidades escolhidas como objeto de pesquisa foram as dez primeiras brasileiras no Webometrics Ranking of World Universities, de julho de 2010. A metodologia consiste em analisar as capturas de telas das páginas iniciais e as respostas a três questões abertas feitas aos setores de comunicação das universidades. Os resultados mostram que o tipo de informação mais freqüente é o Administrativo e institucional e a organização predominante é por Assunto. Acredita-se que o método de análise aqui proposto é útil para o estudo de websites e pode ser aplicado a diferentes tipos de instituições.

Palavras-chave: Arquitetura da Informação. Organização da Informação. Websites. Página inicial.

\begin{abstract}
The aim of this study is to investigate the relationship between the type of information available on website homepages of Brazilian universities and how it is organized. That is, to verify the visibility given to each type of information through the area used in the opening pages of the chosen universities' websites, to identify the universities' vision of their websites, and also, to relate types of information available and types of organization in its opening pages. For this, the article discusses Information Architecture, the presence of universities on the web and the role of its homepages. The motivation of this research is based on identifying a pattern for the information organized on universities websites, since these aggregate content for different target audiences. The universities selected as research object were the Brazilian top ten in the Webometrics Ranking of World Universities in July 2010. The methodology consists of analyzing screenshots of the homepages, and, the answers to three open questions asked to the universities' communications sectors. The results demonstrate that the most frequent type of information is the Administrative and institutional, and also that the predominant organization is by Subject. It is believed that the method of analysis presented here is useful when studying websites and could be applied to different types of institutions.
\end{abstract}

Keywords: Information Architecture. Organization of Information. Websites. Homepage.

\footnotetext{
${ }^{1}$ Graduação em Biblioteconomia. Universidade Federal do Rio Grande do Sul, UFRGS, Brasil. Bibliotecária Especialista em Automação. E-mail: ligiadf@ gmail.com
}

Enviado em: 13/06/2012 - Aceito em: 27/03/2013. 


\section{PESQUISA}

\section{INTRODUÇÃO}

Websites de universidades são fontes de informação institucionais que agregam diversas informações para um variado público-alvo - alunos, ex-alunos, professores, técnicos, comunidade etc. - e suas páginas devem contemplar tipos de informações relevantes a cada um deles. A página inicial pode ser considerada a mais importante de um website, pois, mesmo não sendo a primeira página visitada, é ela quem direciona os usuários aos diferentes conteúdos disponíveis no website; portanto, pode-se supor que a página inicial contemplará todos os aspectos que abrangem a universidade.

A pesquisa foi motivada pela necessidade de identificar padrões de conteúdo e sua organização em websites de universidades brasileiras, considerando que estes agregam muitas informações importantes para diferentes públicos-alvo: alunos, exalunos, vestibulandos, professores, pesquisadores e comunidade em geral.

Assim, o objetivo deste trabalho foi investigar a relação entre o tipo de informação disponibilizada nas páginas iniciais de websites de universidades brasileiras e a forma como ela está organizada. Especificamente: verificar a visibilidade dada a cada tipo de informação por meio da medida da área utilizada nas páginas iniciais dos websites das universidades escolhidas; identificar a visão das universidades escolhidas em relação a seus websites; relacionar tipos de informação disponibilizadas e tipos de organização nas páginas iniciais dos websites das universidades escolhidas. Foram objeto de pesquisa as dez primeiras brasileiras no Webometrics Ranking of World Universities, de julho de 2010.

Para embasar o artigo, a seguir são apresentados aspectos teóricos sobre Arquitetura da Informação, características da presença das universidades na web e importância de suas páginas iniciais.

\section{ARQUITETURA DA INFORMAÇÃO}

A Arquitetura da Informação (AI) para Web é "A combinação de sistemas de organização, rotulagem, busca e navegação em websites e intranets.", segundo Morville e Rosenfeld (2006, p. 4, tradução nossa). Ela contempla diversos aspectos, incluindo estudos de usuários, mas este trabalho contemplará apenas o que se refere à estruturação da informação, que tem como princípios básicos: sistemas de 
organização; sistemas de rotulagem; sistemas de navegação; e sistemas de busca, detalhados a seguir.

Os sistemas de organização agrupam páginas e apresentam as informações dos websites de diversas maneiras. Os sistemas de rotulagem representam o conteúdo de forma compreensível aos usuários. Por fim, os sistemas de navegação e de busca mostram como movimentar-se pelas páginas, através de links de acesso rápido a determinadas seções e de busca no conteúdo. Os sistemas de organização, que são o foco deste trabalho, são detalhados a seguir.

Os sistemas de organização são divididos em esquemas e estruturas, conforme esquematizado na FIGURA 1. Os esquemas de organização são usados para sugerir um modelo mental que os usuários possam entender claramente; enquanto as estruturas são meios primários de navegação.

Figura 1 - Esquematização dos sistemas de organização e suas subdivisões

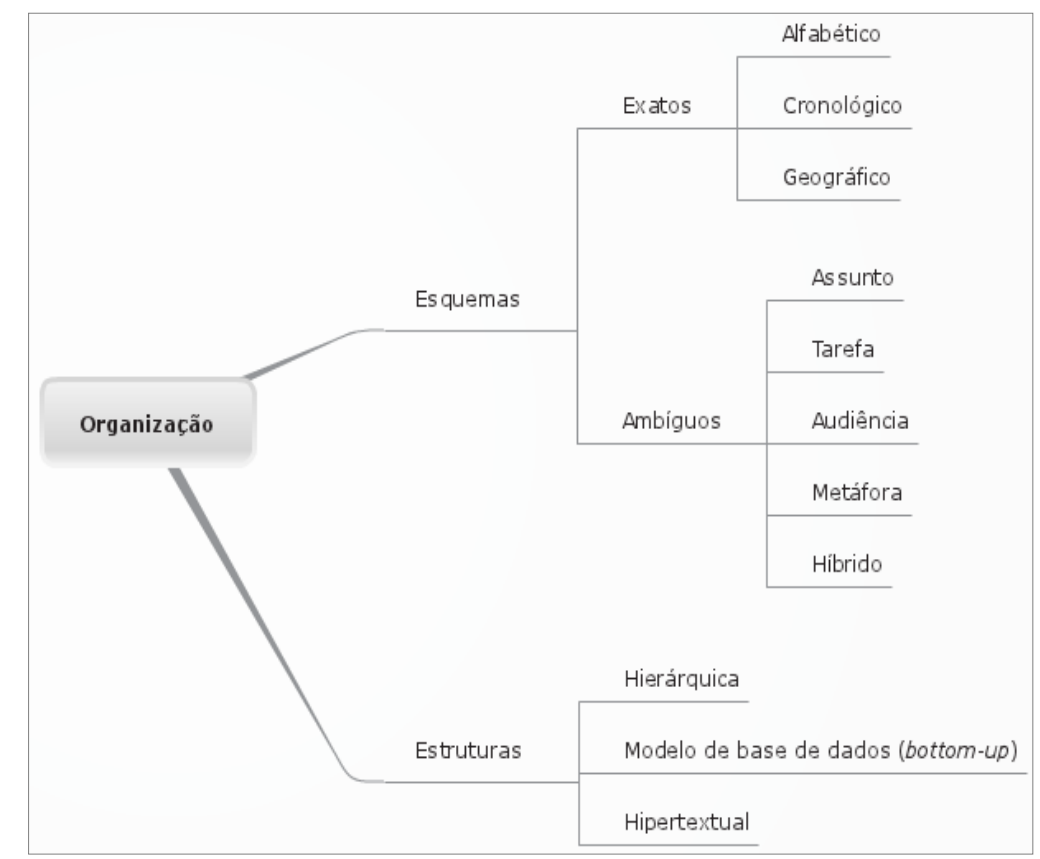

Fonte: Criação da própria autora, baseada em Morville e Rosenfeld (2006).

A estrutura pode ser: Hierárquica, Modelo de base de dados e Hipertextual. A Hierárquica, também chamada de top-down, deve possuir categorias exclusivas e deve ser familiar ao usuário. O Modelo de base de dados, também denominada, utiliza base de dados relacional e é ligado à Arquitetura da Informação através de metadados. Por 
fim, o tipo Hipertextual estrutura a informação de forma alinear e faz a ligação, através de links, entre itens e fragmentos de informação.

Já os esquemas de organização, segundo Morville e Rosenfeld (2006), podem ser Exatos (ou Objetivos) ou Ambíguos (ou Subjetivos). Os primeiros são utilizados quando o usuário sabe o que quer e, por isso, são compostos de seções exclusivas e bem definidas. São eles: Alfabético, cuja função é abrigar outros esquemas; Cronológico, em geral complementado por outros esquemas, pode ser usado para buscar notícias por determinado assunto; e Geográfico que apresenta informações específicas para determinada cidade, região, país.

Os esquemas de informação Ambíguos costumam ser usados quando o usuário tem uma vaga ideia do que quer, e possibilitam ao usuário conectar e relacionar assuntos entre si. Podem ser de cinco tipos: Assunto (ou Tópico), que define a cobertura de assuntos; Tarefa, que é apropriado para antecipar tarefas prioritárias que os usuários vão querer executar; Audiência (ou Público), que possibilita que o conteúdo se altere conforme o perfil selecionado, qual seja aberto (sendo possível escolher diferentes perfis) ou fechado (acesso mediante login e senha); Metáfora, que relaciona um conteúdo novo com um modelo mental conhecido pelo usuário; e Híbrido, que combina diferentes esquemas.

Os desafios da organização da informação na web, apontados por Morville e Rosenfeld (2006), para a utilização dos esquemas de organização são a ambigüidade do idioma, a heterogeneidade dos conteúdos, as diferentes perspectivas das pessoas.

A seguir são apresentadas características de websites de universidades e dos tipos de informação que disponibilizam e características das páginas iniciais de maneira geral.

\section{UNIVERSIDADES ONLINE}

As universidades, assim como outras instituições, empresas, pessoas e grupos, marcam presença online através de seu website (WEB SITE, c2004). Devido ao seu impacto na sociedade, as universidades têm um público-alvo diversificado e uma grande quantidade de informações a ser disponibilizada.

Para Barichello (2004, p. 29), “[...] a visibilidade das instituições depende de sua capacidade de informar e comunicar seus atos.” e, considerando a Internet como uma mídia de convergência com um grande impacto na sociedade atual, é esperado 
que as universidades disponibilizem online informações relevantes para seu público potencial.

Os websites de universidades, assim como os de outros tipos de instituições, podem ser caracterizados como portais corporativos, sucintamente definidos por Dias (2001, p.50) como "[...] um único ponto de acesso a todos os recursos de informação e conhecimento em uma instituição".

Zilber (2006, p. 2) afirma que a função desses portais é "[...] simplificar o acesso de clientes, funcionários, parceiros, investidores, acionistas e fornecedores à companhia através de uma interface personalizada e segura". Além disso, afirma que as universidades são um tipo de empresa cuja missão é "[...] fornecer à comunidade em que se inserem atividades de ensino, pesquisa e extensão, visando a produção e entrega de conhecimento".

A fim de identificar quais são os conteúdos que ganham destaque na página inicial, é necessário estipular categorias de tipos de informação. Popovic et al. (2005) agrupam o conteúdo de um website de universidade em três grupos, exemplificados a seguir:

Pedagógico e pesquisa - inclui informações relacionadas ao planejamento, gerenciamento e colaboração dos cursos. Exemplos: publicação de material pelos professores, para que os alunos acessem; discussões online etc.;

Informação e comunicação - inclui informações a respeito dos estudos e a respeito de relações internacionais e de carreira. Exemplos: datas importantes; exemplos de provas; notícias do escritório internacional etc.;

Administrativo - inclui processos administrativos. Exemplos: inscrição para provas finais; verificação de notas anteriores; emissão de certificados; tarefas para funcionários etc.

Além dos agrupamentos de informações relativas especificamente às universidades, este trabalho leva em conta elementos relativos a websites de maneira geral, por exemplo, os Utilitários e sistema de busca. Para Krug (2008, p, 65): “Os utilitários são links para elementos importantes do site que não façam parte realmente da hierarquia de conteúdo". Podem ser links que auxiliam o usuário a utilizar o website ou que forneçam informações sobre quem o fez. Os sistemas de busca são 
fundamentais em websites com muita informação e, segundo Morville e Rosenfeld (2006), os usuários costumam esperar por uma caixa de busca em todas as páginas.

\section{PÁGINA INICIAL DE WEBSITES}

Para a análise deste trabalho foram escolhidas apenas as páginas inicias devido a sua importância e ao tratamento diferenciado que recebe. Ela é a mais importante em um website, segundo Nielsen e Tahir (c2002), porque, mesmo que nem sempre os usuários entrem no website a partir dela, uma das suas primeiras ações é voltar à página inicial - é ela quem apresenta uma visão geral do que é oferecido pela empresa ou instituição.

Para este trabalho foram consideradas três metáforas da vida offline que podem ser aplicadas às páginas iniciais, segundo Nielsen e Tahir (c2002). A primeira comparação é feita com entrada de prédio, quando a página inicial funciona como um ponto de entrada que afunila o tráfego em diferentes direções e prioriza a destinação dos usuários de acordo com seu interesse.

A segunda metáfora, sumário de livro, pode ser usada quando a página inicial disponibiliza uma visão geral do conteúdo do site de forma hierárquica. Por fim, a terceira, capa de jornal, implica no destaque de notícias e de novos conteúdos periodicamente.

\section{ASPECTOS METODOLÓGICOS}

Para este trabalho foram escolhidas as dez primeiras universidades brasileiras do World Universities' ranking on the web - Latin America, também conhecido por Webometrics Ranking of World Universities ${ }^{2}$, de julho de 2010. Ao todo se classificaram 38 universidades brasileiras, dentre as 100 da América Latina. As universidades selecionadas foram:

a) Universidade de São Paulo (USP), em $2^{\circ}$ lugar;

b) Universidade Estadual de Campinas (UNICAMP), em $4^{\circ}$ lugar;

c) Universidade Federal de Santa Catarina (UFSC), em $6^{\circ}$ lugar;

d) Universidade Federal do Rio de Janeiro (UFRJ), em $7^{\circ}$ lugar;

2 http://www.webometrics.info/

\begin{tabular}{|l|l|l|l|l|l|l|}
\hline (C) Rev. digit. bibliotecon. cienc. inf. & Campinas, SP & v.11 & n.2 & p.176-196 & maio/ago. 2013 & ISSN 1678-765X \\
\hline
\end{tabular}


e) Universidade Federal de Minas Gerais (UFMG), em $9^{\circ}$ lugar;

f) Universidade Federal do Rio Grande do Sul (UFRGS), em $11^{\circ}$ lugar;

g) Pontifícia Universidade Católica do Rio de Janeiro (PUC-Rio), em $12^{\circ}$ lugar;

h) Universidade Federal Fluminense (UFF), em $14^{\circ}$ lugar;

i) Universidade Federal do Rio Grande do Norte (UFRN), em $19^{\circ}$ lugar;

j) Universidade Federal do Paraná (UFPR), em $22^{\circ}$ lugar.

Partiu-se do suposto de que estas universidades produzem grande quantidade de informação para a web e, portanto, oferecem elementos úteis ao trabalho.

A partir dos elementos elencados por Krug (2008), dos esquemas de organização citado por Morville e Rosenfeld (2006) e dos tipos de informação de Popovic et al. (2005), foram elaborados os indicadores que nortearam a análise das páginas iniciais dos websites. O QUADRO 1 esquematiza a utilização de cada indicador referente aos esquemas de organização nesta pesquisa.

Quadro 1 - Explicação dos indicadores de esquemas de organização

\begin{tabular}{|c|c|}
\hline Esquemas de Organização & Descrição \\
\hline Exatos & $\begin{array}{l}\text { Dividem informações em seções bem definidas e } \\
\text { mutuamente exclusivas. }\end{array}$ \\
\hline Alfabético & Agrupamento alfabético dos itens. \\
\hline Cronológico & Agrupamento cronológico dos itens. \\
\hline Geográfico & Agrupamento geográfico dos itens. \\
\hline Ambíguos & $\begin{array}{l}\text { Dividem informações em seções subjetivas, sujeitas às } \\
\text { ambiguidades do idioma e das pessoas. }\end{array}$ \\
\hline Assunto & Agrupa itens de determinado assunto. \\
\hline Tarefa & Agrupa itens de determinada atividade. \\
\hline Audiência & Agrupa itens com mesmo público-alvo. \\
\hline Metáfora & $\begin{array}{l}\text { Agrupa itens cuja descrição remete a um modelo mental } \\
\text { conhecido pelo usuário }\end{array}$ \\
\hline Híbrido & Faz uso de mais de um esquema de organização. \\
\hline
\end{tabular}


O Quadro 2 mostra o que foi observado em cada um dos quatro agrupamentos principais. Considerou-se que os indicadores elencados abrangem a maior parte dos conteúdos existentes nas páginas iniciais dos websites escolhidos.

Quadro 2 - Explicação dos agrupamentos de tipo de informação

\begin{tabular}{l|l}
\hline Agrupamentos de tipo de informação & \multicolumn{1}{|c}{ Descrição } \\
\hline Pedagógico e pesquisa & $\begin{array}{l}\text { Formas de ingresso; cursos de graduação e de pós- } \\
\text { graduação; atividades de pesquisa e de extensão; } \\
\text { link para a Biblioteca; parcerias com governos e } \\
\text { entidades. } \\
\text { Notícias; calendário acadêmico; acesso à intranet; e } \\
\text { Informação e comunicação }\end{array}$ \\
Administrativo e institucional & $\begin{array}{l}\text { Elementos de identificação e de autopromoção; } \\
\text { estrutura da instituição; ouvidoria; legislação; } \\
\text { unidades de ensino; campi; concursos; serviços; } \\
\text { relatórios. } \\
\text { Elementos específicos de websites, como ajuda; } \\
\text { mapa do site; formas de contato; disponibilidade de } \\
\text { conteúdo em outros idiomas; e sistema de busca. }\end{array}$ \\
\hline
\end{tabular}

Em algumas análises também foram considerados outros dois indicadores: elementos de sistema operacional e navegador e, espaços em branco ou sem conteúdo.

As telas dos websites foram coletadas no dia 7 de outubro de 2010, em um computador com sistema operacional Windows XP, resolução de tela 1024x768, no navegador Firefox 3.6.10. Os parâmetros para a coleta foram baseados na média aritmética das estatísticas de uso de janeiro de 2010, disponibilizadas no website Webusability ${ }^{3}$.

Foram capturadas duas imagens para cada universidade: janela (área visível do website, incluindo componentes do sistema operacional e navegador) e página inicial completa (sem componentes de sistema operacional e navegador). As três imagens 
finais de cada universidade ${ }^{4}$ foram: janela original, janela dividida em áreas e página inicial completa.

A coleta referente ao tipo de organização e de informação apresentada nas páginas iniciais foi feita a partir da página inicial completa; já o cálculo referente à área visível foi realizado a partir da imagem da janela, visto que, além dos quatro agrupamentos de tipo de informação, também foram considerados os elementos visuais do navegador e do sistema operacional e os espaços em branco e sem conteúdo.

Para a definição da medida da área de cada elemento foi utilizada a área de retângulo e de quadrado, cujo resultado é a multiplicação da largura pela altura. A área de cada elemento foi dividida pela área total da imagem. Para fins de arredondamento, elementos com cantos arredondados (e outras formas não-lineares) foram capturados como elementos retangulares ou quadrados.

Para verificar a porcentagem do website que é visualizada sem que o usuário precise utilizar a barra de rolagem, foi comparada a área total da segunda imagem com a área da primeira, excetuando-se os elementos de sistema operacional e navegador.

A fim de identificar a visão que as universidades têm sobre seus próprios websites foram elaboradas três questões abertas, enviadas por e-mail no dia 22 de setembro de 2010 aos setores de comunicação ou imprensa das dez universidades escolhidas.

As questões foram:

a) Qual o setor responsável pela atualização e manutenção do website da Universidade? Qual a formação dos profissionais que atuam neste setor?

b) Há uma política para a inserção de conteúdos e para a atualização da página inicial da Universidade? Descreva-a brevemente.

c) Quais os objetivos do website da Universidade?

As respostas foram analisadas de forma qualitativa, em comparação com a divisão da área visualizada acima da dobra das páginas iniciais dos websites.

\section{ANÁLISE E INTERPRETAÇÃO DOS DADOS}


As análises estão dispostas de acordo com os objetivos específicos deste trabalho, organizadas em subseções. São utilizados gráficos e imagens a fim de ilustrar os resultados obtidos.

O primeiro objetivo específico verificou a visibilidade de cada tipo de informação por meio da área visível acima da dobra na página inicial. Também foram contabilizados os elementos do sistema operacional e do navegador, assim como as áreas em branco ou sem conteúdo. O Gráfico 1 ilustra a distribuição das áreas nas dez universidades escolhidas.

Gráfico 1 - Distribuição das áreas dos seis agrupamentos de cada Universidade

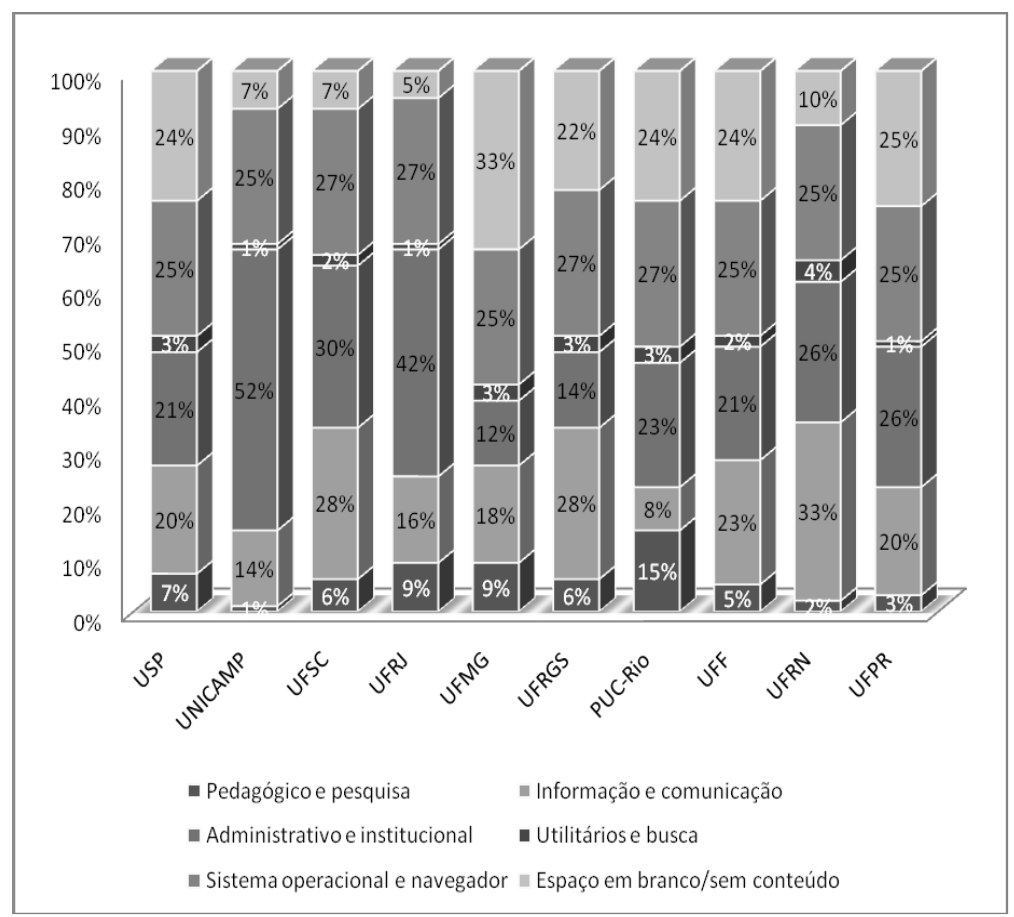

A média da área utilizada para as informações do tipo Pedagógico e pesquisa é de 6,3\%, com destaque para a Unicamp, a UFRN e a UFPR, que têm, respectivamente, apenas 1, 2 e 3\% da área acima da dobra para informações sobre ensino, pesquisa e extensão. A PUC-Rio é a que fornece mais visibilidade às informações do tipo Pedagógico e pesquisa, contabilizando $15 \%$ da área. Mesmo assim, pode-se considerar pouco o destaque a dois elementos que, em conjunto com a extensão, costumam ser chamados de tripé da universidade. 
No que se refere ao agrupamento informação e comunicação, a média da área utilizada é de 20,8\%, sendo a PUC-Rio a que apresenta menor parcela, com apenas 8\%. A UFRN, com 33\%, seguida da UFSC e da UFRGS, com $28 \%$ cada, são as universidades que dão mais destaque a este item. Considerando o valor da média, pode-se constatar a metáfora da página inicial como capa de jornal, apontado por Nielsen e Tahir (c2002), visto que cerca de um quinto da área é utilizado para notícias e destaques de conteúdo.

O agrupamento Administrativo e institucional tem como média o valor de 26,7\% da área visível. No entanto é o agrupamento com maior discrepância de valores: na UFMG e na UFRGS, ocupa 12 e 14\% respectivamente, enquanto na Unicamp chega a 52\%, seguido da UFRJ, com 42\%, e da UFSC, com $30 \%$.

Os Utilitários e busca ocupam, em média, 2,3\% da área, sendo a UFRN a com maior percentual, com apenas 4\%. Apesar de ser um valor baixo, não é inesperado, considerando que estes são elementos auxiliares e que não fazem parte do conteúdo principal da página.

Levando em conta a importância dada por Krug (2008) e por Morville e Rosenfeld (2006) aos sistemas de busca, pode-se dizer que, mesmo com um percentual baixo do agrupamento Utilitários e Busca, as dez universidades contemplam o mínimo de ter uma forma de busca na página inicial. Apenas em uma universidade esta opção não é visível acima da dobra; oito delas apresentam uma caixa de busca, enquanto as outras duas têm apenas link para uma página de busca.

Como era de se esperar, considerando a definição dos parâmetros para a captura de tela, a variação da área ocupada pelos elementos de Sistema operacional e navegador é pequena: apenas $2 \%$ e ocorre apenas nas páginas em que há presença da barra de rolagem horizontal, como é o caso da UFSC. Observa-se, considerando o valor médio de $25,8 \%$, que todas as páginas iniciais perdem cerca de um quarto da tela para elementos gráficos do sistema operacional e do navegador.

Por fim, a média da área com Espaços em branco ou sem conteúdo é de $18,1 \%$, sendo a UFRJ a página inicial com melhor aproveitamento do espaço, tendo apenas 5\% de sua área visível nesta categoria; e a UFMG a com mais espaços em branco, com aproximadamente $33 \%$. 
Outro elemento referente a este objetivo foi a relação entre a área visualizada acima da dobra, descontando os elementos de Sistema operacional e navegador, e o tamanho da página inicial completa. O Gráfico 2 ilustra a relação.

Gráfico 2 - Porcentagem da área visualizada em relação à área da página completa de cada Universidade

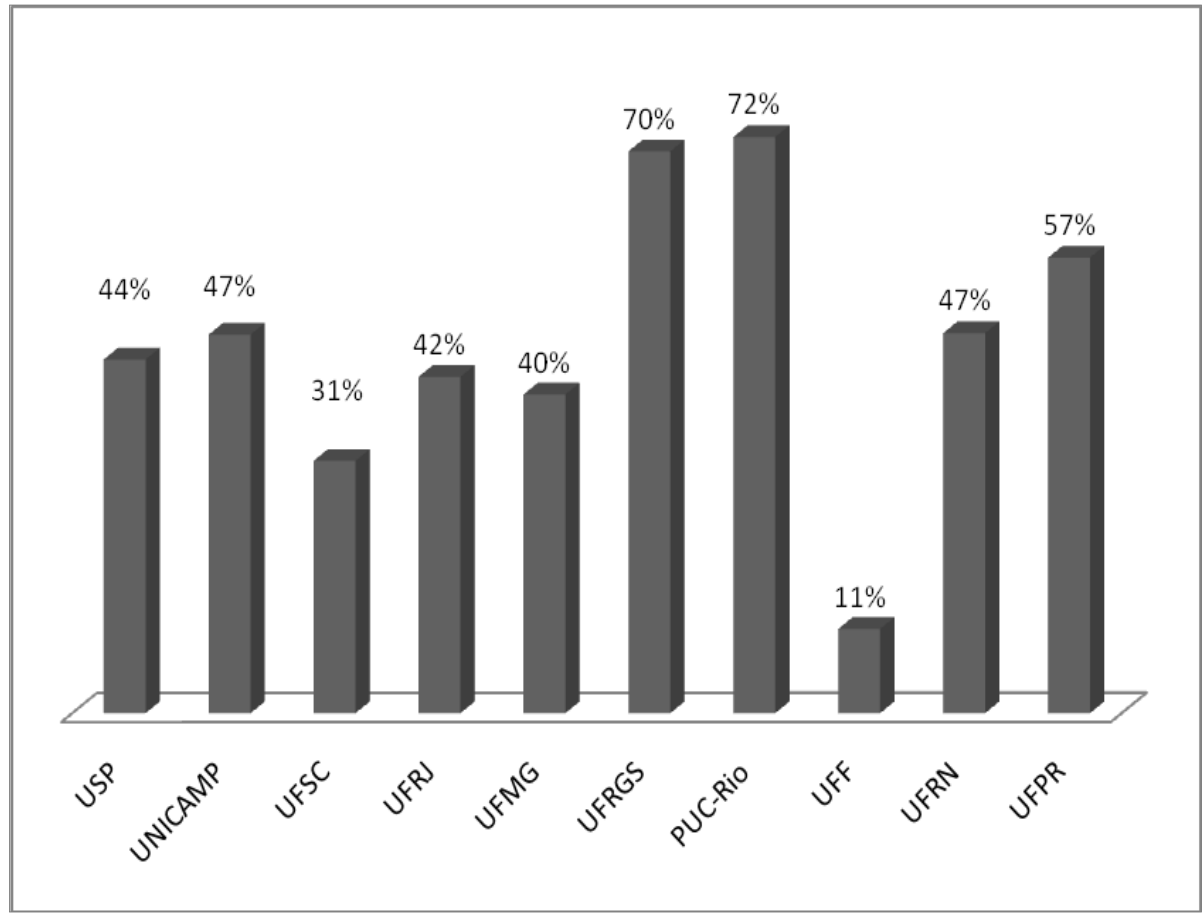

Observa-se uma variação de $61 \%$ e uma média de $46,1 \%$, sendo a UFF a que exibe menor porcentagem da página inicial completa: 11\%; e a PUC-Rio, seguida da UFRGS, as que mais exibem: $72 \%$ e $70 \%$, respectivamente.

Os dados apresentados podem servir como base para uma redefinição das prioridades das páginas iniciais das universidades, considerando os seus objetivos. Esta relação é abordada a seguir.

O segundo objetivo específico do trabalho buscou identificar a visão das universidades escolhidas em relação aos seus websites, através de questões abertas e de identificação que foram enviadas por e-mail às Universidades. Ao todo, foram obtidas respostas de seis universidades, a saber: USP, Unicamp, UFSC, UFRGS, UFF e UFRN, totalizando nove respostas - duas pessoas da USP, da UFSC e da UFRGS enviaram resposta. Não houve retorno de: UFRJ, UFMG, PUC-Rio e UFPR. 
As questões tinham por objetivo identificar o setor responsável e a formação dos profissionais responsáveis pela atualização do conteúdo do website; identificar a existência de uma política de inserção de conteúdo na página inicial; e identificar os objetivos do website. Quanto à identificação, foram questionados o nome e o cargo e/ou setor do respondente.

As respostas à primeira questão foram praticamente unânimes, informando que o setor responsável pela atualização e manutenção dos websites são os de Comunicação das universidades; alguns mencionaram o suporte técnico do setor de Informática, como apoio à manutenção. Esta unanimidade repetiu-se na formação dos profissionais que atuam no setor responsável, pois todas mencionaram jornalistas. Alguns também mencionam webdesigners, estagiários, bolsistas, fotógrafos e apenas a USP, em uma das respostas, menciona bibliotecários.

A segunda questão refere-se à política de inserção e atualização do conteúdo da página inicial. Nem todas as universidades respondentes têm uma política clara quanto à atualização da página inicial e, de maneira geral, as definições existentes contemplam apenas as notícias.

Apenas a USP e a UFRGS informaram documentos (uma Portaria a respeito do website e um Manual com as normas para publicação de notícias, respectivamente). As demais apenas mencionaram, por exemplo, que a página é atualizada diariamente com notícias do interesse dos públicos interno e externo; que ela replica o conteúdo do jornal da universidade e que ela divulga eventos da universidade ou eventos de fora que terão participação de professores. Também foi citada a política de divulgar as atividades de ensino, pesquisa e extensão e informações administrativas dos diversos setores da universidade.

Por fim, sobre os objetivos do website da universidade, destacam-se os seguintes: servir de canal institucional, visando público interno e externo; oferecer acesso aos serviços da instituição; funcionar como uma porta de entrada aos demais websites do sistema, mantidos de maneira descentralizada, de forma a direcionar o usuário à informação desejada; divulgar pesquisas e produção da universidade; divulgar eventos; prestar serviços de utilidade pública; reunir informações sobre a história, missão e estrutura da instituição; divulgar documentos institucionais, editais, 
licitações; oferecer acesso dos alunos e dos servidores à intranet; mostrar o que a universidade oferece; servir como instrumento à comunicação interna e externa.

Percebe-se a menção à outra metáfora utilizada por Nielsen e Tahir (c2002), que compara a página inicial à entrada de um prédio, cujo objetivo é direcionar os diferentes tipos de usuários às informações desejadas.

A fim de verificar se os objetivos das universidades são condizentes com a área ocupada por cada agrupamento de informação, foi feita a comparação a partir das respostas das universidades ao questionário.

De maneira geral, percebeu-se que os objetivos dos websites das universidades são semelhantes, pois privilegiam informações sobre elas mesmas e informações referentes aos acontecimentos recentes, em detrimento às informações sobre ensino, pesquisa e extensão.

Dentre as seis universidades que responderam ao questionário, quatro (USP, Unicamp, UFSC e UFF) têm seus objetivos espelhados na distribuição das informações na área visualizada acima da dobra; em uma delas (UFRGS) há pequenas divergências; e a outra (UFRN) tem os objetivos incertos, portanto não fica clara a relação.

Em relação às quatro universidades que não responderam, pode-se observar que têm distribuições semelhantes às outras, conforme já detalhado na análise do Gráfico 1.

O terceiro e último objetivo específico deste trabalho visou verificar se há relação entre tipos de informação e tipos de organização - ou, como vêm sendo chamados também, entre agrupamentos de informação e esquemas de organização nas amostras. Para isso, foram utilizadas as imagens da página completa.

Após a coleta dos indicadores de tipo de informação e dos esquemas de organização de cada página inicial, foram relacionados os tipos de informação e a organização dentro de cada um dos quatro agrupamentos, a saber: Pedagógico e pesquisa, Informação e comunicação, Administrativo e institucional e Utilitários e busca.

Além dos tipos de organização mencionados nos aspectos metodológicos, foram adicionadas outras duas opções: Não se aplica e Não identificado. A primeira foi utilizada para elementos como o cabeçalho do website e os banners, por não ser 
possível atribuir a eles um dos elementos previsto por Morville e Rosenfeld (2006); a segunda foi utilizada para os indicadores estabelecidos no instrumento de coleta de dados e que não estavam presentes na página inicial analisada.

Estes elementos, no entanto, não foram objeto de análises, assim como o tipo Híbrido de organização, visto que o objetivo era estabelecer a relação, e não apenas elencar os esquemas de organização dos websites.

O primeiro agrupamento analisado foi o Pedagógico e pesquisa. A Figura 2 ilustra a proporção dos esquemas de organização utilizados em relação às dez universidades escolhidas, utilizando o tamanho da palavra como indicador de frequência.

Figura 2 - Proporção dos esquemas de organização do agrupamento Pedagógico e pesquisa

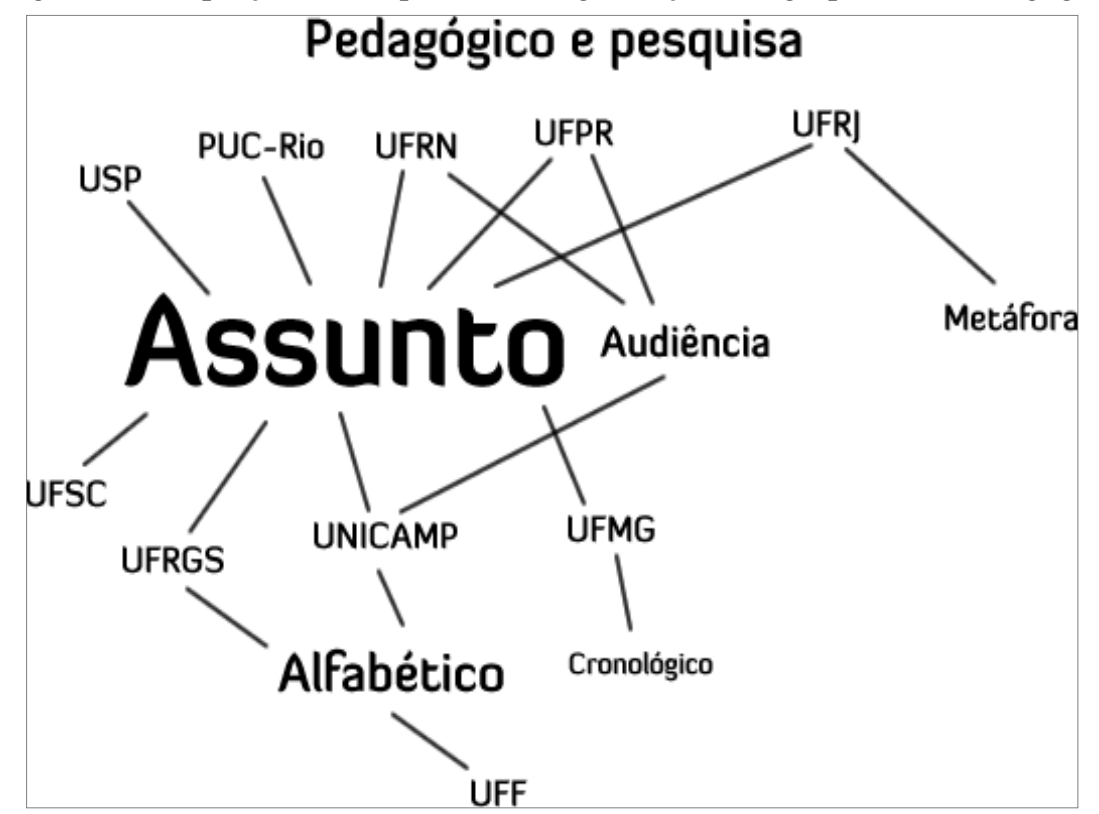

Percebe-se o predomínio da organização por Assunto, utilizada em nove entre as dez universidades. O segundo esquema com maior número de ocorrências é o do tipo Alfabético, utilizado por três universidades.

Observa-se, também, que quatro universidades utilizam apenas um tipo de organização para essas informações; cinco utilizam dois tipos; e apenas uma utiliza três esquemas. Nenhuma utiliza os esquemas Geográfico e por Tarefa.

O agrupamento Informação e comunicação é ilustrado na Figura 3. comunicação

Figura 3 - Proporção dos esquemas de organização do agrupamento Informação e \begin{tabular}{l|l|l|l|l|l|l|l|}
\hline (C) Rev. digit. bibliotecon. cienc. inf. & Campinas, SP & v.11 & n.2 & p.176-196 & maio/ago. 2013 & ISSN 1678-765X \\
\hline
\end{tabular} 


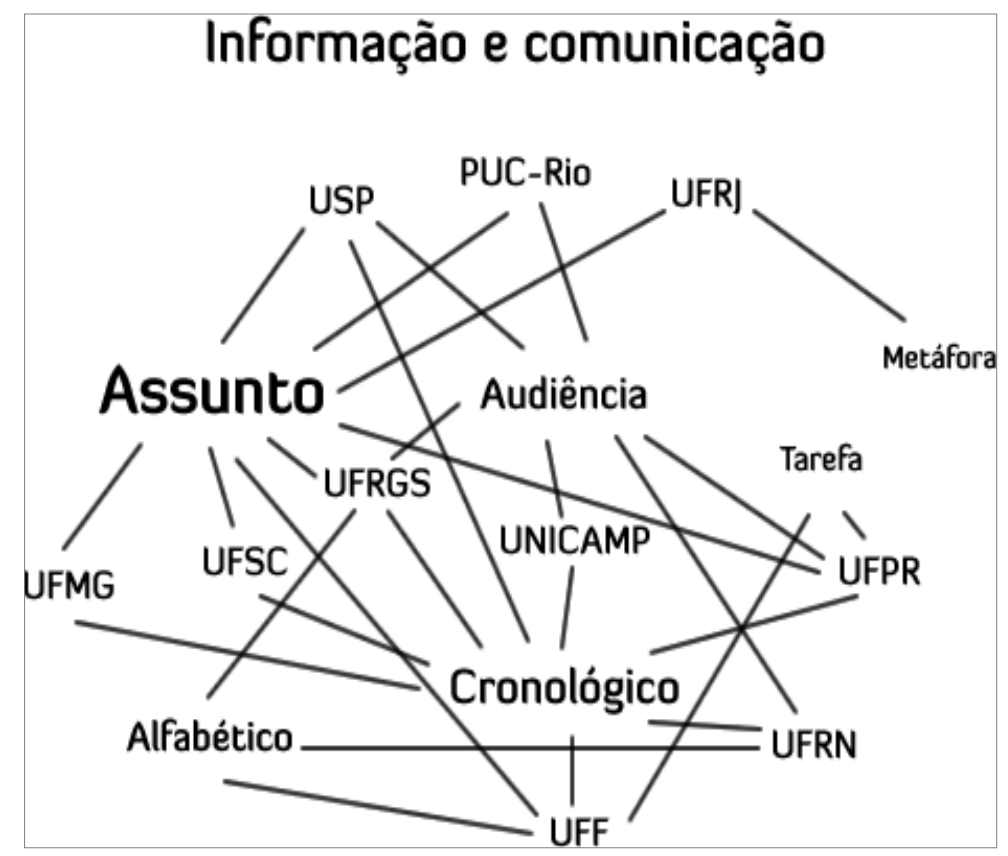

Observando a Figura 3, percebe-se a predominância, embora não absoluta, da organização por Assunto; seguida de Cronológico, Audiência e Alfabético, cujos tamanhos são semelhantes. E, em menor escala, há a presença da organização por Tarefa e por Metáfora, respectivamente. Novamente, não há ocorrências do Geográfico.

Ao contrário do agrupamento anterior, todas as universidades utilizam entre dois e quatro, de um total de sete, esquemas de organização. Supõe-se que a razão seja a abrangência dos indicadores deste agrupamento, que tem informações exclusivas ao público interno (Webmail e Acesso à Intranet) e informações voltadas tanto ao público interno quanto à comunidade na qual está inserida (Calendário acadêmico e Notícias). Essas diferentes abordagens parecem requerer um número maior de tipos de esquemas de organização, a fim de contemplar os diferentes públicos-alvo.

No que diz respeito especificamente ao indicador Notícias, supõe-se que, apesar de muitas estarem organizadas por Assunto, exista uma organização Cronológica implícita.

O terceiro agrupamento analisado foi o Administrativo e institucional, conforme a imagem a seguir. 
Figura 4 - Proporção dos esquemas de organização do agrupamento Administrativo e

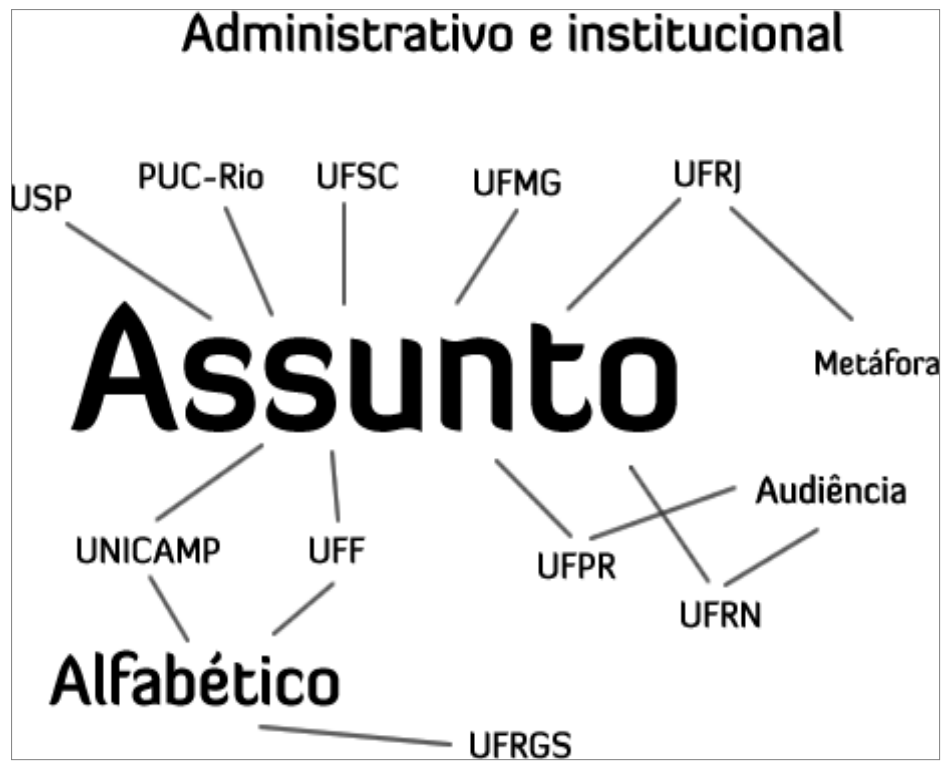

A partir da Figura 4, percebe-se uma clara preferência pela organização por Assunto das informações referentes à própria instituição. Outro fator que influencia o número de ocorrências deste esquema é o número de indicadores que fazem parte deste agrupamento: eram onze indicadores na planilha de coleta de dados - os outros agrupamentos tinham entre quatro e seis indicadores -, além de outros itens não previstos e que foram contabilizados no espaço destinado a este fim. Apenas uma universidade não utiliza este esquema.

O segundo tipo de organização com mais ocorrências é o Alfabético, utilizado por três universidades - e o único da UFRGS. Em menor escala, há ocorrência de organização por Metáfora e por Audiência. Não há ocorrência do Geográfico.

Metade das universidades utilizam um esquema, enquanto a outra metade utiliza dois - o que sugere uma harmonia nas páginas iniciais, em contrapartida ao agrupamento anterior.

O último agrupamento refere-se aos Utilitários e busca, cujos esquemas de organização são mostrados na imagem a seguir.

Figura 5 - Proporção dos esquemas de organização do agrupamento Utilitários e busca 


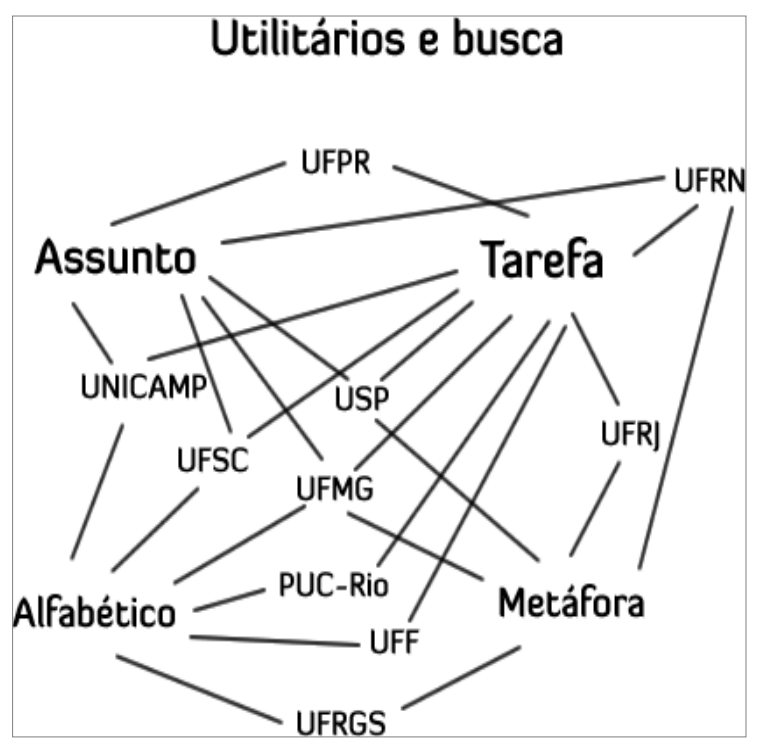

A Figura 5 refere-se aos elementos específicos de websites e apresenta apenas quatro esquemas de organização, em divisão quase equivalente. Os tipos Assunto e Tarefa são ligeiramente mais utilizados que o Alfabético e o por Metáfora. Assim como no agrupamento Informação e comunicação, observa-se que nove universidades utilizam dois ou três esquemas e apenas uma utiliza os quatro.

Destaca-se, também, que nove instituições utilizam o esquema por Tarefa, sendo que, entre essas, oito o utilizam para a caixa de busca. Assim como nos três agrupamentos já citados, não foi observado o esquema Geográfico.

Após a análise dos quatro agrupamentos, percebe-se o surgimento de dois padrões de uso dos esquemas de organização: um que privilegia a organização por Assunto e cujo uso de tipos de esquema por universidade é entre um e três; e outro cujos esquemas utilizados têm um número de ocorrências mais ou menos equivalentes entre si, não tendo nenhum com maior destaque, e no qual as universidades utilizam entre dois e quatro esquemas ao mesmo tempo.

Os padrões referem-se, respectivamente, aos agrupamentos Pedagógico e pesquisa e Administrativo e institucional; e Informação e comunicação e Utilitários e busca.

Outra observação relevante é a não observância do esquema Geográfico, mesmo considerando que algumas das universidades têm mais de um campus e em mais de uma cidade. Supõe-se que, pelas informações da página inicial terem um caráter mais geral, não seja necessária a organização de informações por localidade. 


\section{PESQUISA}

\section{CONSIDERAÇÕES FINAIS}

Após a investigação da relação entre o tipo de informação disponibilizado nas páginas iniciais de websites de universidades brasileiras e a forma como está organizado, objetivo geral deste trabalho, ficou claro que as Universidades escolhidas têm diferentes enfoques ao selecionar os tipos de informação que aparecem na página inicial e, especificamente, acima da dobra. Foi confirmada a utilização de duas das três metáforas sugeridas neste trabalho: página inicial como capa de jornal e como entrada de um prédio.

As páginas iniciais de todas as universidades escolhidas - e poderia se dizer, também, de todos os websites visualizados sob os mesmos parâmetros - perdem cerca de um quarto da área visível para elementos de sistema operacional e navegador.

Todas as universidades que responderam às questões enviadas por e-mail informaram que a atualização do conteúdo do website é feita por profissionais e setores de Comunicação. Apenas uma universidade respondeu ter bibliotecários atuando na atualização do conteúdo do website. Nem todas as universidades respondentes têm uma política clara quanto à atualização da página inicial e, de maneira geral, as definições existentes contemplam apenas as notícias.

Dentre as seis universidades que responderam, quatro têm seus objetivos espelhados na distribuição das informações na área visualizada acima da dobra. As quatro universidades que não responderam apresentam distribuições semelhantes às outras.

Quanto à existência de relação entre tipos de informação e tipos de organização nas páginas iniciais das universidades escolhidas, percebeu-se o surgimento de dois padrões de uso dos esquemas de organização:

a) um que privilegia a organização por Assunto e cuja média de tipos de esquema por universidade é entre um e três - padrão observado nos agrupamentos Pedagógico e pesquisa e Administrativo e institucional;

b) outro cujos esquemas utilizados têm um número de ocorrências mais ou menos equivalentes entre si, não tendo nenhum com maior destaque, e no qual as universidades utilizam entre dois e quatro esquemas ao mesmo tempo - padrão observado nos agrupamentos Informação e comunicação e Utilitários e busca. 


\section{PESQUISA}

Em síntese, o problema levantado na introdução - "Que tipos de informação as universidades disponibilizam nas páginas iniciais de seus websites e como eles estão organizados?" - foi respondido: o tipo de informação observado mais freqüentemente foi o Administrativo e institucional e a organização predominante é por Assunto para as dez universidades analisadas. Acredita-se que o método de análise aqui proposto é útil para o estudo de websites e pode ser aplicado a diferentes tipos de instituições. 


\section{REFERÊNCIAS}

BARICHELLO, Eugenia Mariano da Rocha. Modelos e práticas de comunicação na universidade: identidade, territorialidade e legitimação institucional. In: BARICHELLO, Eugenia Mariano da Rocha (Org.). Visibilidade midiática, legitimação e responsabilidade social: dez estudos sobre as práticas de comunicação na Universidade. Santa Maria:

FACOS/UFSM, 2004. Cap. 1, p. 13-44.

DIAS, Cláudia Augusto. Portal corporativo: conceitos e características. Ciência da Informação, Brasília, DF, v.30, n.1, p.50-60, jan./abr. 2001. Disponível em:

<http://revista.ibict.br/ciinf/index.php/ciinf/article/view/223/198>. Acesso em: 30 maio 2010.

KRUG, Steve. Não me faça pensar!: uma abordagem de bom senso à usabilidade na web. 2 . ed. Rio de Janeiro: Alta Books, 2008.

MORVILLE, Peter; ROSENFELD, Louis. Information Architecture for the World Wide Web. 3rd ed. Sebastopol: O'Reilly, 2006.

NIELSEN, Jakob; TAHIR, Marie. Homepage usability: 50 websites deconstructed. [Indianopolis]: New Riders, c2002.

POPOVIC, Ales et al. Web Triad: the Impact of Web Portals on Quality of Institutions of Higher Education - Case Study of Faculty of Economics, University of Ljubljana, Slovenia. Issues in Informing Science and Information Technology, Santa Rosa, CA, v. 2, p. 313324, 2005. Disponível em: 〈http://2005papers.iisit.org/I25f94Popo.pdf〉. Acesso em: 31 maio 2010.

WEB SITE. In: REITZ, Joan M. Online Dictionary for Library and Information Science. [Santa Barbara, CA]: Libraries unlimited, c2004. Disponível em:

<http://lu.com/odlis/odlis_w.cfm\#website >. Acesso em: 22 jun. 2010.

ZILBER, Silvia Novaes. O uso do portal corporativo universitário para gestão do conhecimento: comparação entre portais de universidades públicas e privadas. In: SIMPÓSIO DE GESTÃO DA INOVAÇÃO TECNOLÓGICA, 24., 2006, Gramado. [Anais]... Rio de Janeiro: ANPAD, 2006.

\section{Como citar este artigo:}

FREITAS, Lígia Dias de. Tipos, organização e visibilidade de informações em páginas iniciais de websites de universidades brasileiras. Rev. digit. bibliotecon. cienc. inf., Campinas, SP, v. 11, n. 2, p.176-196, maio/ago. 2013. ISSN 1678-765X. Disponível em: <http://www.sbu.unicamp.br/seer/ojs/index.php/rbci> 